\title{
What Factors are Associated with Flourishing? Results from a Large Representative National Sample
}

\author{
Marijke Schotanus-Dijkstra ${ }^{1,2} \cdot$ M. E. Pieterse ${ }^{2}$. \\ C. H. C. Drossaert ${ }^{2}$ - G. J. Westerhof ${ }^{2} \cdot$ R. de Graaf ${ }^{1}$ • \\ M. ten Have ${ }^{1}$ J. A. Walburg ${ }^{2}$ - E. T. Bohlmeijer ${ }^{2}$
}

Published online: 11 June 2015

(C) The Author(s) 2015. This article is published with open access at Springerlink.com

\begin{abstract}
Flourishing is the ultimate end-state in psychology and a key-concept in the field of positive psychology research. Flourishers are those individuals with both high levels of hedonic well-being and eudaimonic well-being. Although many researchers have focused on one or another of these domains, only a few have investigated the comprehensive state of flourishing. The purpose of this study was to examine the prevalence of flourishing and its association with socio-demographics, personality traits and situational factors. This study used data from the second wave of the Netherlands Mental Health Survey and Incidence Study-2 (NEMESIS-2), a national representative sample of adults in The Netherlands $(\mathrm{n}=5303 ; 2010-2012)$. Findings were compared to having either high hedonic well-being or high eudaimonic well-being. Results showed that $37 \%$ of the respondents were flourishers, mainly characterized by high levels of conscientiousness and extraversion and low levels of neuroticism. The situational factors of social support and positive life-events were significantly associated with flourishing when the analysis was controlled for socio-demographics and personality traits. Flourishing was most distinct from high hedonic well-being and showed parallelism with high eudaimonic well-being. More research is needed to establish a preferred flourishing instrument with validated cutoff points for flourishing and to understand the processes of situational factors that may underlie the promotion of flourishing. We recommend longitudinal designs and experience sampling studies to investigate the unique and modifiable predictors of flourishing. In addition, future research should include intervention studies that examine through which hedonic and eudaimonic pathways flourishing can be achieved.
\end{abstract}

Marijke Schotanus-Dijkstra

m.schotanus@utwente.nl; mdijkstra@trimbos.nl

1 Trimbos Institute, Netherlands Institute of Mental Health and Addiction, P.O. Box 725, 3500 AS Utrecht, The Netherlands

2 Department of Psychology, Health and Technology, University of Twente, P.O. Box 217, 7500 AE Enschede, The Netherlands 
Keywords Flourishing · Well-being · Personality · Positive life-events · Social support · Physical health

\section{Introduction}

Researchers have become increasingly interested in the concept of flourishing (Diener et al. 2010; Henderson et al. 2013; Huppert and So 2013; Keyes 2002; Seligman 2011). Flourishing is defined as having high levels of both hedonic well-being and eudaimonic well-being (Huppert 2009; Huppert and So 2013; Keyes 2002) although different operationalizations of flourishing circulate in the literature (see Hone et al. 2014). Hedonic wellbeing comprises subjective or emotional well-being which, in turn, consists of the components happiness, life-satisfaction and a positive-negative affect balance (Diener 1984). Psychological well-being and social well-being are part of eudaimonic well-being and include a wide variety of components such as meaning, engagement, purpose in life, positive relations and personal growth (Keyes 2002; Ryan et al. 2008; Ryff 1989). Flourishers seem to have excellent mental and physical health and are more resilient to vulnerabilities and challenges in life than non-flourishers (Bergsma et al. 2011; Diener and Seligman 2002; Huppert 2009; Kobau et al. 2011; Lyubomirsky et al. 2005, b; Ryff and Singer 1998, 2008; Veenhoven 2008).

A few studies combined a measure of hedonic well-being with a measure of eudaimonic well-being to compare four groups of individuals: those with high hedonic and high eudaimonic well-being, those with high hedonic well-being and low eudaimonic wellbeing, those with low hedonic well-being and high eudaimonic well-being, and those with low hedonic and low eudaimonic well-being (Huta and Ryan 2010; Keyes et al. 2002; Peterson et al. 2005). Each study used different assessments of well-being and, consequently, different categorization methods to identify each group. For example, Huta and Ryan (2010) assessed the intention of undergraduates to participate in hedonic activities (i.e. "seeking pleasure" or "seeking relaxation") and eudaimonic activities (i.e. seeking to pursue excellence or a personal ideal" or "seeking to use the best in yourself") with the median on these intentions to allocate high or low well-being. Results showed that individuals with both high hedonic and high eudaimonic motives-as compared to individuals in the other three groups - had the most favorable outcomes on vitality, awe, inspiration, transcendence, positive affect and meaning. Some of these outcomes were more strongly related to hedonic activities, while others more strongly related to eudaimonic activities, suggesting that both hedonic and eudaimonic activities should be pursued for the most optimal and diverse well-being (Huta and Ryan 2010). These conclusions were in line with a previous study examining pleasure, engagement and meaning as the three orientations to happiness (Peterson et al. 2005). A major strength of this inquiry was that the authors found the same beneficial results for various applied categorization methods (Peterson et al. 2005). A different type of study computed the tertiles on a subjective well-being scale and a psychological well-being scale to allocate participants to one of the four groups and found different patterns for each group in relation to socio-demographics and personality traits (Keyes et al. 2002). For example, flourishers were older and better educated than languishers, while age was highest in the predominantly hedonic group and education was highest in the predominantly eudaimonic group (Keyes et al. 2002). Taken together, high levels of both hedonic and eudaimonic well-being often lead to the most favorable 
outcomes compared to high levels of one well-being domain combined with low levels on the other well-being domain (Huta and Ryan 2010; Keyes et al. 2002; Peterson et al. 2005).

Despite the central focus of flourishing in positive psychology research (Huppert 2009; Rose 2008; Seligman 2011), only a few studies have investigated the prevalence of flourishing in the general population and the characteristics of flourishers. In this paper, we examine the prevalent rate of flourishing, defined as having high levels of both hedonic and eudaimonic well-being, in a national representative sample of adults in The Netherlands. We also examine how various characteristics are associated with flourishing, including socio-demographics, personality traits and the situational factors social support, life-events and physical health status. This study builds upon former research in that we compare flourishers to those individuals with only high hedonic well-being (i.e. not in combination with low eudaimonic well-being) or only high eudaimonic well-being (i.e. not in combination with low hedonic well-being). Also, to the best of our knowledge, this is the first study to examine the relationship between the above mentioned situational factors and flourishing.

\subsection{Prevalence of Flourishing}

Available epidemiological studies of flourishing used different study populations and operationalizations of flourishing, which makes it difficult to compare the results. One of the largest studies on flourishing was conducted by Huppert and So (2013), who used a representative sample of 43,000 respondents in 22 European countries. They developed a conceptual framework and identified ten dimensions of flourishing clustered around three factors. An individual is "flourishing" when Factor 1 (i.e. positive emotion) is present, in combination with at least four out of five Factor 2 dimensions (i.e. emotional stability, vitality, optimism, resilience, self-esteem) and at least three out of four Factor 3 dimensions (i.e. engagement, competence, meaning and positive relationships). The study of Huppert and So (2013) revealed major differences in the prevalence of flourishing between Northern, Eastern, and Southern/Western European countries. For instance, Denmark led the ranking with $40.6 \%$ of flourishers, followed by Switzerland $(30.2 \%)$, and at the bottom-end were Slovakia, Russia and Portugal with respectively 9.9, 9.4 and $9.3 \%$ flourishers (Huppert and So 2013). These differences between groups of countries correspond to the happiness data of countries previously collected in the World Database of Happiness (Veenhoven 2010).

Keyes $(2002,2005)$ has provided the comprehensive approach for conceptualizing and studying flourishing. Following Keyes' definition, flourishers are those individuals with high levels of emotional, social and psychological well-being. The first dimension can be seen as part of the hedonic domain, and the latter two dimensions as part of the eudaimonic domain. According to Keyes (2002), the opposite of flourishing is languishing, and those individuals who are neither flourishing nor languishing are defined as having moderate mental health. A national representative study of adults in the US assessed each well-being dimension with a different questionnaire and demonstrated that there were $18 \%$ flourishers and $17 \%$ languishers (Keyes 2002). This study set the stage for the development of the Mental Health Continuum-Short Form (MHC-SF), an instrument for assessing well-being and flourishing. A first evaluation of this 14-item questionnaire in a South African adult sample revealed a prevalence of $20 \%$ for flourishing and $12 \%$ for languishing (Keyes et al. 2008). The MHC-SF is now widely used in well-being research, but less is known about the prevalence of flourishing in national representative studies using this instrument. 


\subsection{Characteristics of Flourishers}

The research into the characteristics of flourishers to date has tended to focus on hedonic or eudaimonic well-being. Moreover, only a few studies have been published about predictors of flourishing. In addition, the evidence for flourishing has hitherto been based on a narrow empirical sample because the currently available studies on factors related to flourishing all relied on a single database, the Midlife in the United States (MIDUS) study (Keyes 2002, 2005, 2007; Keyes et al. 2002; Keyes and Simoes 2012). Consequently, in order to expand the existing knowledge, we built a more comprehensive frame of reference for our study into flourishing by incorporating studies that had explored emotional, psychological and social well-being.

A substantial body of research suggests that socio-demographics, such as female gender, higher national and personal income, higher education, living with a partner and paid employment are positively related to subjective well-being (Diener et al. 1995, 1999; Diener and Ryan 2009; Veenhoven 1996, 2008) and to psychological well-being (Ryff and Keyes 1995; Ryff and Singer 2008). Higher educational attainment, higher household income and higher employment status also show strong relationships with social wellbeing (Cicognani et al. 2008; Keyes 1998; Keyes and Shapiro 2004). Studies about flourishing demonstrated that males, adults between 45 and 54 years, adults with 16 or more years of education and married adults were most likely to flourish (Keyes 2002; Keyes et al. 2002; Keyes and Simoes 2012). Socio-demographics often added least to the explained variance in well-being outcomes when other variables were taken into account (Demir and Weitekamp 2007; Keyes et al. 2002; Lamers et al. 2012b).

Of all studied predictors, personality traits seem to have the strongest relationship with subjective and psychological well-being, especially low neuroticism, high extraversion and high conscientiousness (DeNeve and Cooper 1998; Keyes et al. 2002; Lamers et al. 2012b; Steel et al. 2008). The theory of chronic happiness (Lyubomirsky et al. 2005b) states that there is a stable genetic happiness set point that is unlikely to change. This genetic set point has been estimated to contribute $50 \%$ to long-term happiness. In line with this theory, different studies found that personality traits are strongly correlated with well-being and often explain most of the variance in well-being outcomes when taking other variables into account (Demir and Weitekamp 2007; Keyes et al. 2002; Lamers et al. 2012b; Steel et al. 2008). A twin study even suggested that the underlying genetic structure for subjective well-being is the same as for individual differences in personality traits (Weiss et al. 2008). High levels of extraversion and conscientiousness and low levels of neuroticism have also been found to relate to the state of flourishing (Keyes et al. 2002).

Socio-demographics and personality traits are well-studied in relation to well-being, but less is known about situational factors such as social support, life-events and physical health status. Studies have demonstrated that having more social support and social participation relate to higher subjective and psychological well-being (Diener and Seligman 2002, 2004; Huppert 2009; Keyes 1998), long-term happiness (Caunt et al. 2012), and resilience, vitality and mental health (Barry 2009; Lehtinen et al. 2005). The relationship between subjective well-being and positive and negative life-events is yet unclear. Not all life-events can be objectively rated as positive or negative when it comes to well-being outcomes. For example, getting married could be objectively rated as a positive life-event, but its effects varied from initially a higher level of life-satisfaction to lower subjective well-being in the long-term (Luhmann et al. 2012). Divorce, on the other hand, could be objectively rated as a negative life-event, but, in fact, led to a small increase in subjective 
well-being in the short and long-term (Luhmann et al. 2012). The hedonic treadmill theory claims that every life-event that provokes positive or negative emotional reactions has a short-term effect on the level of subjective well-being before it returns to its baseline state. However, new empirical evidence suggests that there are individual differences in the level and number of baseline states and that some baseline states can change (Diener et al. 2006; Lucas 2007). Finally, subjective and psychological well-being have a positive relationship with physical health outcomes such as lower physical impairment in daily activities (Keyes 2002, 2005), less physical diseases and conditions (Keyes 2007), faster recovery of physical illness, and longevity (Lamers et al. 2012a; Lyubomirsky et al. 2005a). Yet, it is unknown to what extent these situational factors are associated with flourishing. A recent study by Keyes and Simoes (2012) found no significant differences in common physical diseases between flourishers and non-flourishers.

To summarize, the science of flourishing is still in its infancy. Therefore, the purpose of the present study was to contribute to the science of flourishing by estimating the prevalence of flourishing in a representative adult population sample in The Netherlands and to examine what factors were associated with flourishing. We expected a stronger relationship between flourishing and the personality traits of extraversion, neuroticism and-to a lesser degree-conscientiousness, than with socio-demographics and situational factors. To address the lack of consistent evidence regarding the relationship between flourishing and different situational factors, we explored whether social support, life-events and physical health status were associated with flourishing, over and above socio-demographics and personality traits, without any specific hypotheses. Finally, we explored differences and similarities in prevalence and associated characteristics between flourishing on the one hand and having high levels of either hedonic well-being or eudaimonic-wellbeing on the other.

\section{Method}

\subsection{Design and Sample}

We used data from the Netherlands Mental Health Survey and Incidence Study-2 (NEMESIS-2), which is a nationally representative Dutch population study designed to examine the mental health status of non-institutionalized persons aged 18-64 years in The Netherlands (De Graaf et al. 2010). NEMESIS-2 is a three-wave longitudinal study with a 3 year interval. We used the cross-sectional results of 5303 respondents who participated in the second wave of NEMESIS-2 because, in this wave, the MHC-SF was included to measure well-being and flourishing. We also used data on socio-demographics, personality traits and situational factors (i.e. social support, life-events and physical health status) from the first and second wave.

At baseline, participants were recruited from a random sample of 184 of the 443 existing Dutch municipalities between November 2007 and July 2009. In the 184 municipalities, a random sample of private households was drawn from postal registers. The adult with the most recent birthday was selected for participating in a face-to-face interview to complete different questionnaires. If necessary, this adult person with sufficient fluency in the Dutch language was contacted by phone or a home visit at least ten times, and these contacts are described in detail elsewhere (De Graaf et al. 2010, 2012, 2013). The response rate was $65.1 \%$ for the first wave $(\mathrm{N}=6646)$. The sample was 
nationally representative, although younger participants were somewhat underrepresented. In the second wave, respondents were re-interviewed three years later between November 2010 and June 2012, with a response rate of $80.4 \%(\mathrm{~N}=5303)$. Attrition was related to younger age, lower educational level, not having a partner, not being in paid employment and not being born in The Netherlands, but not associated with mental disorders and their clinical characteristics after controlling for socio-demographics (De Graaf et al. 2013a, b).

\subsection{Measurements}

\subsubsection{Well-Being and Flourishing}

The Dutch version of the 14-item MHC-SF measures well-being during the past month with one hedonic dimension and two eudaimonic dimensions, each with at least three theoretically based components (i.e. items about feelings) per dimension (Keyes et al. 2008; Lamers et al. 2011). Emotional well-being (hedonic well-being) consists of the happiness, positive affect and life-satisfaction components (e.g. "In the past month, how often did you feel happy?"). The eudaimonic dimensions are social and psychological well-being. Social well-being consists of the following components: social contribution, social integration, social actualization, social acceptance and social coherence (e.g. "In the past month, how often did you feel that our society is becoming a better place for people?"). Psychological well-being comprises the six components of Ryff (1989): self-acceptance, environmental mastery, positive relations with others, personal growth, autonomy and purpose in life (e.g. "In the past month, how often did you feel confident to think or express your own ideas and opinions?"). Respondents rated every item on a 6-point Likert scale, where $0=$ never, $5=($ almost $)$ always. The mean score was computed, and higher scores indicated higher well-being. Hotdeck imputation (Myers 2011) was used to impute the missing data on one or more items from 339 individuals (6.4\%). The MHC-SF has excellent psychometric properties and has been validated in different countries (Keyes et al. 2008, 2010) including The Netherlands (Lamers et al. 2011, 2012b). The internal consistency (Cronbach's alpha) of the total wellbeing scale was .87 , and the internal consistencies of the subscales were .82 for emotional well-being, .66 for social well-being and .79 for psychological well-being.

The continuous measure of well-being can be used to determine the level of positive mental health. However, in this study, we were specifically interested in flourishers: those individuals who scored highest on both hedonic and eudaimonic well-being. We, therefore, used Keyes's criteria (2006; Keyes et al. 2008) to generate well-being categories. Individuals who scored 4 or 5 on one or more items of emotional well-being possessed the highest levels of hedonic well-being $(0=n o ; 1=y e s)$, and individuals who scored 4 or 5 on six of the eleven items of the combined scale of social and psychological well-being possessed the highest levels of eudaimonic well-being $(0=n o ; 1=$ yes $)$. Flourishers were those individuals with a score of 1 on both well-being domains. Languishers were those individuals who scored 0 or 1 on one or more items of emotional well-being and who scored 0 or 1 on six of the eleven items of the combined scale of social and psychological well-being. The persons who were neither flourishing, nor languishing were labelled as moderately mentally healthy.

\subsubsection{Socio-demographics}

Socio-demographics included age, gender, educational attainment, living situation, employment situation and urbanization. Educational attainment was measured during the first wave of NEMESIS-2, and all other socio-demographics during the second wave. In the 
statistical analysis (see Sect. 2.2.5), we treated educational attainment as a continuous variable ranging from 1 (primary education) to 4 (higher professional education, university) and we transformed living situation into a dummy code $(0=$ alone; $1=$ not alone $)$ because living alone was the strongest significant indicator versus the other categories.

\subsubsection{Personality Traits}

Two subscales of the Eysenck Personality Questionnaire-Revised Short Scale (EPQ-RSS) were used to measure neuroticism (i.e. emotional instability, worrying, nervousness) and extraversion (i.e. impulsivity, outgoing, lively) (Eysenck et al. 1985, 1976; Sanderman et al. 1995). Both scales consisted of 12 items with ratings of yes (1) or no (0). For each personality trait, a total score was computed with higher scores indicating higher levels of the trait ranging from 0 to 12 . Cronbach's alpha was .80 for neuroticism and .83 for extraversion. These two subscales were measured in the first wave, and, therefore, not measured at the same time as well-being.

Conscientiousness (i.e. organized, responsible, ambitious) was measured on the second wave with one scale of the NEO Five Factor Inventory (NEO-FFI) (Costa and McCrae 1992). Participants rated the 12 items on a scale ranging from (1) totally disagree to (5) totally agree. The total score ranged from 12 to 60 with higher scores indicating higher levels of conscientiousness. Cronbach's alpha was .81.

\subsubsection{Situational Factors}

Social support was measured during the second wave with two questions for each of the following resources in the close network: the partner, family and friends, and neighbors. The questions referred to the extent to which respondents could (1) rely on their resources for help if they had a problem and (2) open up to them if they needed to talk about worries. The four response categories ranged from 1 (not at all) to 4 (a lot). The mean score on both questions was used to indicate the respondent's perceived social support from a resource. Because not everyone had a partner, the total mean score was calculated from either two or three resources for social support (Ten Have et al. 2014). In the analyses, we only used this total score for the level of social support.

Major negative life-events ( 9 items) and major positive life-events (6 items) during the past twelve months before the second wave were measured with a scale based on the Brugha Life-events Section (Brugha et al. 1985). Examples of negative life-events were "your child, brother, sister, parent or partner died" or "you were fired or became unemployed," and examples of positive life-events were "you found a new partner" or "a close family-member or your partner recovered from a serious disease or injury." Participants could also report other life-events in the open answer category. These answers were checked to make sure that they belonged to one of the life-events categories. Any open answers of a participant that remained were counted as one life-event for each individual because this category contained additional information. The number of life-events in our sample ranged between 0 and 5 for negative life-events, and between 0 and 4 for positive life-events.

Physical health status during the past month was assessed during the second wave by the Dutch version of the RAND 36-item Health Survey 1.0 (RAND-36; Van der Zee and Sanderman 1993). The RAND-36 consists of 36 items encompassing eight dimensions: physical functioning, social functioning, role limitations due to physical problems, role limitations due to emotional problems, mental health, vitality, bodily pain and general health. Response categories differ between items, and every summed subscale was transformed to a scale of 
0-100 with higher scores indicating better functioning (Stewart et al. 1988). Cronbach's alpha ranged between .76 for general health and .92 for physical functioning. Scores on the eight dimensions were aggregated into the Physical Component Summary (PCS) and Mental Component Summary (MCS). The subscale scores were transformed into z-scores using Dutch means and standard deviations (Van der Zee and Sanderman 1993) and multiplied with the US factor score coefficients to facilitate international comparisons. These coefficients were summed over all eight subscales. To obtain normally distributed transformed summary scores with a mean of 50 and an SD of 10, the PCS and MCS sums were multiplied by 10 followed by adding 50 (Van der Zee and Sanderman 1993; Ware et al. 1994). In the analyses, we only used the PCS score because this score represented the physical health status of individuals which was the main interest in our current study. The MCS score was already reflected in our primary outcome of well-being and flourishing.

\subsubsection{Statistical Analyses}

We obtained the estimates of the prevalence of flourishing with descriptive statistics. Because there were few languishers in our study (see Sect. 3), we created a dummy variable for flourishers (1) versus non-flourishers (0) for subsequent analyses. We then generated descriptive statistics of the socio-demographics for flourishers and non-flourishers, and we tested the differences with Chi square statistics and ANOVA. For the categorical variables with more than one category, we generated indicator contrasts that tested for significant differences between flourishers and non-flourishers for each category compared to all other categories $(p<.001)$. Bivariate correlations were examined using Pearson's correlation coefficient between flourishing and the independent variables. Then, all significantly associated factors with flourishing were included in a stepwise multiple logistic regression analysis with three steps. The first step included socio-demographics because these were relatively stable characteristics and, in previous studies, have added little to explaining the variance in well-being (Demir and Weitekamp 2007; Lamers et al. $2012 \mathrm{~b}$ ). In the second step, the personality traits were added because of their expected high level of explained variance in flourishing (Demir and Weitekamp 2007; Lamers et al. 2012b; Steel et al. 2008). Situational factors were added in the third step in order to explore if these factors were associated with flourishing above and beyond personality traits and socio-demographics. All the statistical analyses mentioned above were repeated with the binary classifications of high hedonic well-being (1) versus no high hedonic well-being (0) and high eudaimonic well-being (1) versus no high eudaimonic well-being (0).

We performed all analyses with both unweighted and weighted data. The weight factor was constructed based on gender, age, cohabitation status, employment status, educational level, place of birth, urbanization level and the weight factor in the first wave (De Graaf et al. 2010, 2012, 2013a). In this paper, we only report the unweighted data because the differences between the unweighted data and weighted data were negligible. All analyses were performed with SPSS 21.0. An alpha of .001 was applied due to the large sample size.

\section{Results}

Our first aim was to generate estimates of the prevalence of flourishers, languishers and the moderately mentally healthy. These estimates in the general Dutch population showed that $36.5 \%$ were flourishers, $1.6 \%$ were languishers, and the majority had moderate mental 
health $(61.9 \%)$. We also found that $78.3 \%$ of the Dutch population possessed high hedonic well-being and $38.2 \%$ possessed high eudaimonic well-being (Table 1). In our sample, a combination of high hedonic well-being and non-high eudaimonic well-being was more frequent $(41.8 \%)$ than a combination of high eudaimonic well-being and nonhigh hedonic well-being $(1.8 \%)$.

Due to the lack of languishers in our study, languishers and the moderately mentally healthy were joined into a single category of non-flourishers. In the subsequent analyses, non-flourishers were contrasted with flourishers.

The second aim of our study was to examine the characteristics of flourishers. As shown in Table 2, flourishing was significantly associated with all socio-demographics $(p \leq .001)$, except for urbanization level. The flourishing group contained relatively younger individuals, more females and higher educated individuals compared to the nonflourishing group. Flourishers were less likely to live alone, and they were more often in paid employment than non-flourishers. Of all socio-demographic categories, the highest percentage of flourishers was found in the youngest age category of 18-24 years (45.2\%).

The same patterns emerged when examining high levels of either hedonic well-being or eudaimonic well-being (data not in Table). However, high hedonic well-being was not significantly associated with younger age and higher education. High eudaimonic wellbeing was not significantly associated with gender and all living situation categories, but individuals with high eudaimonic well-being were less likely to live alone when contrasted with not living alone $(p=.001)$. Urbanization level did not reach statistical significance in any test.

Pearsons correlation coefficients were used to examine the associations between flourishing, personality traits and the situational factors of social support, life-events and physical health status (Table 3). All variables, except negative life-events, correlated significantly with flourishing $(p<.001)$. A medium effect was found for conscientiousness $(r=.28)$, while small to medium effects were found for extraversion $(r=.22)$, neuroticism $(r=-.18)$ and social support $(r=.16)$. Although almost all inter-correlations were statistically significant, correlations were low with small or small-to-medium effects. To summarize, flourishers were mainly characterized by high levels of conscientiousness and extraversion, and low levels of neuroticism. Physical health status and positive life-events were weakly associated with flourishing.

When examining the correlations between either high hedonic well-being or high eudaimonic well-being and the independent variables (data not in Table), the same conclusions were drawn except for a significant association between high hedonic well-being and negative life-events $(r=-.06)$ and a non-significant association between high hedonic well-being and positive life-events $(p=.10)$.

Results of the stepwise multiple logistic regression analysis showed that the full model with socio-demographics, personality traits and situational factors significantly explained

Table 1 Prevalence of combinations of high/non-high hedonic well-being and high/non-high eudaimonic well-being $(\mathrm{N}=5303)$

\begin{tabular}{lllr}
\hline & $\begin{array}{l}\text { Non-high hedonic } \\
\text { well-being }(\%)\end{array}$ & $\begin{array}{l}\text { High hedonic } \\
\text { well-being }(\%)\end{array}$ & 61.8 \\
\hline Non-high eudaimonic well-being & 19.9 & 41.8 & 38.2 \\
High eudaimonic well-being & 1.8 & 36.5 & 78.3 \\
\hline
\end{tabular}


Table 2 Descriptives of flourishers and non-flourishers $(\mathrm{N}=5303)$

\begin{tabular}{|c|c|c|c|}
\hline & $\begin{array}{l}\text { Flourishers } \\
(\mathrm{n}=1935) \\
\mathrm{n}(\%)\end{array}$ & $\begin{array}{l}\text { Non-flourishers } \\
(\mathrm{n}=3368) \\
\mathrm{n}(\%)\end{array}$ & $p$ \\
\hline \multicolumn{4}{|l|}{ Socio-demographics } \\
\hline Age $(\mathrm{M} ; \mathrm{SD})^{\mathrm{a}}$ & $46.3(12.6)$ & $48.4(12.2)$ & $<.001$ \\
\hline Age categories ${ }^{\mathrm{b}}$ & & & $<.001$ \\
\hline $18-24$ & $90(45.2)$ & $109(54.8)$ & \\
\hline $25-34$ & $308(42.5)$ & $416(57.5)^{\mathrm{c}}$ & \\
\hline $35-44$ & $481(38.9)$ & $754(61.1)$ & \\
\hline $45-54$ & $482(35.5)$ & $874(64.5)$ & \\
\hline $55+$ & $574(32.1)$ & $1215(67.9)^{\mathrm{c}}$ & \\
\hline Gender $^{\mathrm{b}}$ & & & .001 \\
\hline Male & $814(34.2)$ & $1566(65.8)$ & \\
\hline Female & $1121(38.4)$ & $1802(61.6)$ & \\
\hline Education $^{\mathrm{b}}$ & & & $<.001$ \\
\hline Primary education & $62(27.4)$ & $164(72.6)$ & \\
\hline Lower secondary education & $430(31.0)$ & $958(69.0)^{\mathrm{c}}$ & \\
\hline Higher secondary education & $630(36.5)$ & $1098(63.5)$ & \\
\hline Higher professional education, University & $813(41.5)$ & $1148(58.5)^{\mathrm{c}}$ & \\
\hline Living situation ${ }^{\mathrm{b}}$ & & & $<.001$ \\
\hline With partner and children & $820(39.3)$ & $1267(60.7)^{\mathrm{c}}$ & \\
\hline With partner without children & $602(36.1)$ & $1064(63.9)$ & \\
\hline Single parent & $104(36.2)$ & $183(63.8)$ & \\
\hline Alone & $328(30.8)$ & $736(69.2)^{\mathrm{c}}$ & \\
\hline With parents & $61(40.7)$ & $89(59.3)$ & \\
\hline With other(s) & $20(40.8)$ & $29(59.2)^{\mathrm{c}}$ & \\
\hline Living situation (recoded) ${ }^{\mathrm{b}}$ & & & $<.001$ \\
\hline Alone & $328(30.8)$ & $736(69.2)$ & \\
\hline Not alone & 1607 (37.9) & $2632(62.1)$ & \\
\hline $\mathrm{Job}^{\mathrm{b}}$ & & & $<.001$ \\
\hline Not in paid employment & $442(30.9)$ & $988(69.1)$ & \\
\hline In paid employment & $1493(38.5)$ & $2380(61.5)$ & \\
\hline Urbanization $^{\mathrm{b}}$ & & & .133 \\
\hline Small village & $278(40.5)$ & $408(59.5)$ & \\
\hline Village & $400(34.6)$ & $755(65.4)$ & \\
\hline Town & $406(35.6)$ & $733(64.4)$ & \\
\hline Small city & $488(37.0)$ & $832(63.0)$ & \\
\hline Big city & $363(36.2)$ & $640(63.8)$ & \\
\hline
\end{tabular}

${ }^{a}$ Differences between groups tested with ANOVA

b Differences between groups tested with $X^{2}$-test on all categories

c Statistically significant difference between groups for this category compared to the other categories $(p<.001)$ 
Table 3 Pearson's correlations between flourishing, personality traits and situational factors $(\mathrm{N}=5303)$

\begin{tabular}{|c|c|c|c|c|c|c|c|c|}
\hline & $\mathrm{M}(\mathrm{SD})$ & Flourishing & $\mathrm{E}$ & $\mathrm{N}$ & $\mathrm{C}$ & SS & NLE & PLE \\
\hline \multicolumn{9}{|l|}{ Personality traits (range) } \\
\hline Extraversion $(0-12)$ & $8.5(3.0)$ & $.22 *$ & & & & & & \\
\hline Neuroticism (0-12) & $2.4(2.6)$ & $-.18^{*}$ & $-.25^{*}$ & & & & & \\
\hline Conscientiousness (12-60) & $45.8(5.3)$ & $.28 *$ & $.20^{*}$ & $-.23^{*}$ & & & & \\
\hline \multicolumn{9}{|l|}{ Situational factors (range) } \\
\hline Social support (1-4) & $3.4(.6)$ & $.16^{*}$ & $.15^{*}$ & $-.23^{*}$ & $.17 *$ & & & \\
\hline Negative life-events $(0-5)$ & $.7(.9)$ & -.01 & .01 & $.10 *$ & -.04 & $-.07 *$ & & \\
\hline Positive life-events (0-4) & $.5(.8)$ & $.07 *$ & $.07 *$ & $.08^{*}$ & .00 & -.01 & $.24^{*}$ & \\
\hline $\begin{array}{l}\text { Physical health status } \\
\quad(0-100)\end{array}$ & $50.7(8.9)$ & $.06^{*}$ & $.06^{*}$ & $-.15^{*}$ & $.09 *$ & $.11^{*}$ & $-.13^{*}$ & -.03 \\
\hline
\end{tabular}

$* p<.001$

$M$ mean, $S D$ standard deviation, $E$ extraversion, $N$ neuroticism, $C$ conscientiousness, $S S$ social support, $N L E$ negative life-events, $P L E$ positive life-events

Table 4 Logistic regression coefficients related to flourishing, high hedonic well-being and high eudaimonic well-being $(\mathrm{n}=5135)$

\begin{tabular}{|c|c|c|c|c|c|c|}
\hline & \multicolumn{2}{|c|}{ Flourishing } & \multicolumn{2}{|c|}{ High hedonic well-being } & \multicolumn{2}{|c|}{$\begin{array}{l}\text { High eudaimonic well- } \\
\text { being }\end{array}$} \\
\hline & $\mathrm{b}$ & $\mathrm{OR}^{1}(95 \% \mathrm{CI})$ & $\mathrm{b}$ & $\mathrm{OR}^{1}(95 \% \mathrm{CI})$ & $\mathrm{b}$ & $\mathrm{OR}^{1}(95 \% \mathrm{CI})$ \\
\hline \multicolumn{7}{|c|}{ Step 1: Socio-demographics } \\
\hline Age & -.1 & $.99(.99-1.00)$ & .00 & $1.00(.99-1.01)$ & -.01 & $.99(.99-1.00)$ \\
\hline Gender & .24 & $1.27(1.12-1.44)^{*}$ & .36 & $1.43(1.23-1.66)^{*}$ & .19 & $1.21(1.06-1.37)$ \\
\hline Education & .14 & $1.15(1.07-1.24)^{*}$ & -.01 & $.99(.91-1.07)$ & .16 & $1.17(1.09-1.26)^{*}$ \\
\hline Living situation & .01 & $1.01(.86-1.19)$ & .34 & $1.40(1.18-1.66)^{*}$ & -.08 & $.93(.79-1.09)$ \\
\hline \multirow[t]{2}{*}{ Job } & -.03 & $.97(.82-1.14)$ & -.08 & $.92(.77-1.11)$ & -.07 & $.93(.79-1.10)$ \\
\hline & & $\mathrm{R}^{2}=.023^{*}$ & & $\mathrm{R}^{2}=.027^{*}$ & & $\mathrm{R}^{2}=.022 *$ \\
\hline \multicolumn{7}{|l|}{ Step 2: Personality traits } \\
\hline Extraversion & .11 & $1.12(1.10-1.15)^{*}$ & .05 & $1.05(1.03-1.08)^{*}$ & .12 & $1.13(1.10-1.15)^{*}$ \\
\hline Neuroticism & -.11 & $.90(.87-.92)^{*}$ & -.15 & $.87(.84-.89)^{*}$ & -.10 & $.90(.88-.93)^{*}$ \\
\hline \multirow[t]{2}{*}{ Conscientiousness } & .11 & $1.11(1.10-1.13)^{*}$ & .08 & $1.08(1.07-1.10)^{*}$ & .11 & $1.11(1.10-1.13)^{*}$ \\
\hline & & $\Delta \mathrm{R}^{2}=.154^{*}$ & & $\Delta \mathrm{R}^{2}=.126^{*}$ & & $\Delta \mathrm{R}^{2}=.157 *$ \\
\hline \multicolumn{7}{|l|}{ Step 3: Situational factors } \\
\hline Social support & .34 & $1.40(1.25-1.57)^{*}$ & .41 & $1.51(1.34-1.70)^{*}$ & .35 & $1.42(1.27-1.59)^{*}$ \\
\hline Negative life-events & -.02 & $.98(.91-1.06)$ & -.11 & $.89(.82-.97)$ & -.02 & $.99(.92-1.06)$ \\
\hline Positive life-events & .19 & $1.20(1.11-1.31)^{*}$ & .14 & $1.15(1.04-1.27)$ & .19 & $1.21(1.12-1.32)^{*}$ \\
\hline \multirow[t]{2}{*}{ Physical health status } & .00 & $1.00(1.00-1.01)$ & .01 & $1.01(1.00-1.02)$ & .00 & $1.00(1.00-1.01)$ \\
\hline & & $\Delta \mathrm{R}^{2}=.012^{*}$ & & $\Delta \mathrm{R}^{2}=.018^{*}$ & & $\Delta \mathrm{R}^{2}=.013^{*}$ \\
\hline
\end{tabular}

$O R$ odds ratio. $\mathrm{R}^{2}=$ Nagelkerke $\mathrm{R}^{2}$. Results are for the final model

$* p<.001$ 
$19 \%$ of the variance in flourishing (Omnibus $X^{2}=764.47, d f=12, p<.001$ ). Sociodemographics (step 1) explained around $2 \%$ of the variance in flourishing (Table 4). In agreement with our expectations, we found that the personality traits (step 2) were most strongly related to flourishing with an additional $R^{2}$ of $15 \%$. The situational factors (step 3 ) also added to the explained variance in flourishing when controlling for socio-demographics and personality traits $\left(\Delta R^{2}=1 \%\right)$.

When we determined the unique relationships of the individual variables with flourishing, we included both categorical and continuous variables with different ranges in scores in the logistic regression analysis. As a result, the odds ratios do not reflect true differences in the strength of the relationships. For this purpose, the Wald statistic was used to designate the strongest variables. Our results showed that flourishing was most strongly associated with conscientiousness [Wald $X^{2}(1)=239.32$ ], extraversion [Wald $X^{2}$ $(1)=92.02$ ], neuroticism [Wald $X^{2}(1)=52.08$ ], social support [Wald $X^{2}(1)=33.72$ ] and positive life-events [Wald $X^{2}(1)=18.79$ ]. Age, living situation, employment situation, negative life-events and physical health status were not significantly associated with flourishing in the full model.

The regression analysis with flourishing as a dependent variable was compared to analyses with either high hedonic well-being or high eudaimonic well-being as a dependent variable. The full regression models explained $17 \%$ of the variance in high hedonic wellbeing (Omnibus $X^{2}=601.03, d f=12, p<.001$ ) and $19 \%$ of the variance in high eudaimonic well-being (Omnibus $X^{2}=784.34, d f=12, p<.001$ ). High hedonic wellbeing was most strongly associated with conscientiousness [Wald $X^{2}(1)=121.33$ ], neuroticism [Wald $X^{2}(1)=101.44$ ], social support [Wald $X^{2}(1)=47.64$ ], gender [Wald $X^{2}(1)=22.31$ ] and extraversion [Wald $X^{2}(1)=17.91$ ], while the same rank order was found for high eudaimonic well-being as compared to flourishing with the strongest relationships for conscientiousness [Wald $X^{2}(1)=242.10$ ], extraversion [Wald $X^{2}$ $(1)=102.90$ ], neuroticism [Wald $X^{2}(1)=47.59$ ], social support [Wald $X^{2}(1)=36.88$ ] and positive life-events [Wald $X^{2}(1)=20.76$ ]. Of all significant relationships, most differences were found between high hedonic well-being and flourishing. Flourishing showed a positive relationship with higher education and positive life-events, while these factors were not significantly related with high hedonic well-being. An opposite pattern was found for living situation, indicating that individuals with high hedonic well-being were less likely to live alone, and that living situation was not significantly associated with flourishing. The only difference found between high eudaimonic well-being and flourishing was the factor of gender, which was significant for flourishing (i.e. women were more likely to flourish) but not for high eudaimonic well-being. We also performed regression analyses with an additional step in the high hedonic and high eudaimonic analysescontrolling for the other domain-which led to the same overall conclusions.

\section{Discussion}

The aim of this study was to estimate the prevalence of flourishing in a large representative adult population sample in The Netherlands and to examine various factors associated with this optimal mental health state. Flourishers have high levels of both hedonic well-being and eudaimonic well-being, and in the current study we compared this flourishing state with having high levels of either hedonic well-being or eudaimonic well-being. 


\subsection{Prevalence of Flourishing}

Our study revealed that $36.5 \%$ of the Dutch were flourishers and $1.6 \%$ were languishers. The prevalence of flourishing was almost the same as for having high eudaimonic wellbeing (38.2\%), while the vast majority of individuals in The Netherlands possessed high hedonic well-being $(78.3 \%)$. The fact that we used another instrument, the 14-item MHC$\mathrm{SF}$, is a likely explanation for the discrepancy between the amount of flourishers in the current study and the $20 \%$ flourishers found for the Netherlands by Huppert and So (2013). A recent study by Hone et al. (2014) has demonstrated that Huppert and So's framework revealed conservative estimates of flourishing compared to the MHC-SF and other instruments that assess flourishing. In the same population sample in New Zealand, Hone et al. (2014) found that the prevalence of flourishing ranged from $24 \%$, when measured with Huppert and So's framework, to $39 \%$ with the MHC-SF, $41 \%$ with the Flourishing Scale (Diener et al. 2010) and $47 \%$ with the PERMA Profiler (Seligman 2011). We also found considerably more flourishers and less languishers than has been found in the US (Keyes 2002: $18 \%$ flourishers and $17 \%$ languishers) and in South Africa (Keyes et al. 2008: 20\% flourishers and $12 \%$ languishers). However, these results should be interpreted with care because the assessment and categorization method for flourishing differed from our study (Keyes 2002) or the sample was non-representative (Keyes et al. 2008).

To our knowledge, the prevalence of high hedonic well-being and high eudaimonic well-being have not been reported before. Based on our sample, it seems that it is relatively easy for the Dutch to meet the hedonic criteria of flourishing: scoring high on at least one of the three emotional well-being items (Keyes 2006; Keyes et al. 2008). This cut-off value for high hedonic well-being could be debated, since it is based on US data and originates from a study wherein a variety of instruments assessed well-being (Keyes 2002). More specifically, individuals had to score high on the six-item positive affect scale or they had to score high on one question about life-satisfaction to meet the hedonic well-being criteria for flourishing (Keyes 2002, 2005). Nonetheless, different world rankings showed that, of 156 countries, The Netherlands ranks fourth for happiness (i.e. positive affect, negative affect and life-satisfaction) (Helliwell et al. 2013) and, of 149 countries, fifteenth for lifesatisfaction (Veenhoven 2010). The high level of hedonic well-being in The Netherlands could be a result of socio-economic advantages and culturally specific indicators such as a lower level of national income inequality, higher levels of individualism, social equality and human rights. These factors have been found to predict national subjective well-being (Diener et al. 1995), but it remains unknown if these factors are also relevant for eudaimonic well-being and flourishing.

Whereas almost $80 \%$ of the population of this study sample possessed high levels of hedonic well-being, only $38 \%$ possessed high levels of eudaimonic well-being. Thus, the prevalence of flourishing seems almost completely explained by the amount of high eudaimonic well-being. This finding seems in contrast with previous studies. For example, the highest average scores in the US and South Africa were for psychological well-being and social well-being (Keyes 2005; Keyes et al. 2008), and in seven prosperous countries, participants reported higher levels for meaningfulness than they did for happiness and lifesatisfaction (Delle Fave et al. 2011). Further, we found an asymmetrical relationship between hedonic well-being and eudaimonic well-being as has previously been found by Waterman (1993; Waterman et al. 2008). That is, while high hedonic well-being was also experienced with non-high eudaimonic well-being (41.8\%), the reverse was less common 
(1.8\%). However, our findings are in contrast with prior research wherein more equal groups were found (Huta and Ryan 2010; Keyes et al. 2002). Since our study was correlational in nature, causal relationships between hedonic and eudaimonic well-being-or possible reciprocal relationships as proposed by Kashdan et al. (2008) — has yet to be studied.

\subsection{Characteristics of Flourishers}

As expected, of all the included variables in the regression analysis, personality traits were most strongly related to flourishing. Flourishers were characterized by higher levels of conscientiousness and extraversion and a lower level of neuroticism, which was in contrast with the majority of studies that found the strongest relationships for neuroticism or extraversion (Demir and Weitekamp 2007; Diener and Seligman 2002; Huppert 2009; Lamers et al. 2012b; Lyubomirsky et al. 2005b; Rentflow et al. 2009; Steel et al. 2008). A possible explanation for the strong relationship of conscientiousness found in our study could be that conscientiousness was measured at the same time as flourishing, while extraversion and neuroticism were measured three years earlier. While most researchers have concentrated their work on hedonic well-being and on the personality traits of neuroticism and extraversion (DeNeve and Cooper 1998; Steel et al. 2008), our findings suggest that conscientiousness might have a stronger relationship with flourishing than previously thought. In fact, by definition, conscientious individuals are characterized by setting challenging goals for themselves and maintaining the discipline necessary to achieve those goals. These specific characteristics of conscientiousness might be especially relevant for flourishers, since most operationalizations of these constructs contain an engagement component (Hone et al. 2014).

The variance in high well-being and flourishing was least explained by socio-demographics. This finding is in agreement with previous empirical studies about predictors of well-being (Demir and Weitekamp 2007; Lamers et al. 2012b). We found gradual patterns from more flourishers in younger age groups to less flourishers in older age groups, and from more flourishers with higher education to less flourishers with lower education. This pattern for education is in accordance with Keyes and Simoes (2012), but they found a pyramid pattern for age with the highest percentage of flourishers in the 45-54 age group and the lowest percentages of flourishers in the younger age groups. In the full regression model of our study, only higher education continued to be significantly related to flourishing. Furthermore, we found that female gender was significantly related to flourishing, which is in contrast with Keyes and Simoes' (2012) finding that male gender was significantly associated with flourishing.

To the best of our knowledge, this is the first study to describe the relationship between flourishing and the situational factors of social support, life-events and physical health status. We found that social support and positive life-events contributed significantly to the explained variance in flourishing, after controlling for socio-demographics and personality traits. Previous studies have shown the great importance of social support for the experience of well-being (Barry 2009; Caunt et al. 2012; Demir and Weitekamp 2007; Diener and Seligman 2002, 2004; Huppert 2009; Keyes 1998; Lehtinen et al. 2005), and the present study provided additional evidence with respect to the experience of flourishing. A remarkable finding of our study was that positive life-events, but not negative life-events, showed a relationship with flourishing. Little is known about the effects of positive lifeevents on well-being and flourishing since the study of negative life-events predominates the literature. Nevertheless, Roepke (2013) recently reported that positive events had the 
similar effects on growth as negative events. That is to say, greater growth was experienced after more meaningful events or after events in which the participants were strongly engaged, independent from the event being positive or negative in nature. Although our results suggest that positive life-events have an impact on flourishing and that being confronted with negative life-events does not, more studies are needed to replicate these results. Finally, compared to previous studies, it is somewhat surprising that we did not found a relationship between physical health status and flourishing (Keyes 2002, 2005, 2007; Lamers et al. 2012a). It could be that our measure of physical health status is genuinely different from other indicators of physical health such as physical impairment in daily activities or the presence of chronic diseases and conditions.

We were also interested in exploring differences and similarities between the characteristics of flourishers and the characteristics of having high levels of either hedonic wellbeing or eudaimonic well-being. Our logistic regression results suggest that high hedonic well-being is genuinely different from the state of flourishing, while high eudaimonic wellbeing showed strong parallelism with flourishing characteristics. However, there was also considerable overlap in that personality traits explained most of the variance in the dependent variables, and that the situational factors (mainly social support) explained additional variance above and beyond personality traits and socio-demographics. Our findings correspond with recent theories and empirical evidence that, rather than studying either domain alone, the investigation of both hedonic and eudaimonic well-being provides more insight into the multifaceted construct of well-being (Huta and Ryan 2010; Henderson et al. 2013; Kashdan et al. 2008; Peterson et al. 2005; Seligman 2011; Waterman 2008). For the pursuit of the highest levels of well-being (i.e. flourishing), characteristics associated with high eudaimonic well-being seem to be decisive. However, this topic warrants more research that engages other samples and various instruments.

\subsection{Strengths and Limitations}

This study adds to the literature in that most of the research in the field of positive psychology has focused on hedonic or eudaimonic well-being instead of on their combination and, more specifically, on the combination of the highest levels of well-being. Two major strengths of the present study are that we: (1) used a large national representative study in a non-English speaking country and (2) included situational factors in explaining flourishing. As these factors are, to some extent, more modifiable, they may be of interest for public mental health and policy. We were also able to use the MHC-SF, a widely validated and reliable instrument to measure well-being and flourishing. In this way, we could compare our results with previous studies that had also used this instrument. Finally, to our knowledge, we were the first to compare flourishing with having high levels of either hedonic or eudaimonic well-being.

The results of our study are limited by the use of a cross-sectional design, which makes it difficult to draw conclusions about causality. However, educational attainment, extraversion and neuroticism were measured during the first wave and, therefore, not measured cross-sectionally. Our results are also limited by the use of a binary classification of high hedonic well-being and high eudaimonic well-being instead of continuous measures. Our main interest was to examine flourishing, which is essentially a categorical variable (Keyes 2002; Keyes et al. 2002; Hone et al. 2014; Huppert and So 2013). For reasons of direct comparison, we applied the same criteria to each well-being construct. 


\section{Practical Implications and Future Research}

The findings of the current study have implications for future research and practice. First, whereas governments are now increasingly interested in well-being research to refine their policy (Barry 2009; Forgeard et al. 2011), most nationwide population studies include only hedonic well-being measures (Biswas-Diener et al. 2010). Our research indicates that conclusions about the prevalence and characteristics of high levels of well-being depends on which well-being domain is measured. We recommend researchers to either include measures of flourishing or eudaimonic well-being besides measures of hedonic well-being. In order to compare prevalent rates of flourishing among nations and to further unravel determinants of flourishing, it seems essential to reach a consensus about a preferred flourishing instrument with validated cut-off points in a variety of countries. Future validation studies could examine optimal criteria for having the highest prevalence of flourishing together with the lowest prevalence of mental illness.

Second, to attain the ultimate goal for the future that by the year $2051,51 \%$ of the world population should be flourishing (Seligman 2011), more research is needed to find specific and modifiable antecedents of flourishing that could then be addressed in new interventions. Based on our study, hypotheses for future research might explore beneficial pathways to flourishing such as strengthening social support, savoring positive life-events and the use of specific characteristics of conscientiousness like goal-striving. However, longitudinal designs are necessary to examine predictors of flourishing. In addition, experience sampling studies could also be relevant to identifying modifiable-and theoretically relevant-antecedents of flourishing, and to gain insight into the processes involved into daily flourishing activities and the influence of social support and (positive) life-events. For example, future studies could use the Day Reconstruction Method or diary method and include measures of positive emotion, engagement, positive relationships, meaning and accomplishment, which are the ingredients of flourishing according to the Well-being Theory of Seligman (2011). Since we found strong relationships between personality traits and flourishing, it would also be interesting to examine how these traits interact with antecedents of flourishing. Next, experimental intervention studies are needed to investigate which modifiable factors may contribute to achieving a state of flourishing and which target groups would benefit most.

Third, in our sample, wherein $78 \%$ of the Dutch population possessed high hedonic well-being, it seems fruitful to put most effort in increasing the level of eudaimonic wellbeing to promote flourishing in The Netherlands. This approach would be in line with the eudaimonic living model based on the self-determination theory (Ryan et al. 2008), which assumes that the basic needs for competence, autonomy and relatedness are required for flourishing (Deci and Ryan 2000). However, previous studies using continuous measures of well-being found contradicting results with regard to which well-being domain is better or most beneficial. For example, when researchers pre-defined daily activities as promoting hedonic or eudaimonic well-being, more engagement in eudaimonic activities were found (Steger et al. 2008). But when individuals themselves indicated daily activities as promoting hedonic or eudaimonic well-being, they engaged more often in hedonic activities (Henderson et al. 2013). There are also indications that the pursuit of hedonic well-being activities (i.e. those that enhance feeling good and relaxation) increases short term wellbeing, whereas the pursuit of eudaimonic well-being activities (i.e. those that enhance excellence and growth) leads to long term well-being (Huta and Ryan 2010). In addition, positive emotions (i.e. hedonic well-being) seem to create upward spirals to more 
eudaimonic activities which eventually leads to flourishing (Catalino and Fredrickson 2011; Fredrickson and Losada 2005). More research is needed to identify differences and similarities between (high) hedonic well-being, (high) eudaimonic well-being and flourishing.

To conclude, the Dutch seem to be a flourishing population compared to other nations such as the US, but the prevalence of flourishing warrants further examination in a variety of countries. Whereas personality traits were most strongly associated with flourishing, the situational factors of social support and positive life-events were also important in explaining the variance of flourishing. We found considerable overlap when we compared the characteristics of flourishers with the characteristics of either high hedonic or high eudaimonic well-being, but high hedonic well-being was most discriminative from flourishing in prevalence and characteristics. Future studies are needed to confirm our findings. More research is especially needed to establish a preferred instrument and culturally valid cut-off points for the assessment of flourishing, which can then be used to further unravel the prevalence and characteristics of flourishers worldwide.

Acknowledgments NEMESIS-2 is conducted by the Netherlands Institute of Mental Health and Addiction (Trimbos Institute) in Utrecht. Financial support was received from the Ministry of Health, Welfare and Sport, with supplement support from the Netherlands Organization for Health Research and Development (ZonMw), the Genetic Risk and Outcome of Psychosis (GROUP) Investigators, and the National Institute for Public Health and Environment (RIVM).

Open Access This article is distributed under the terms of the Creative Commons Attribution 4.0 International License (http://creativecommons.org/licenses/by/4.0/), which permits unrestricted use, distribution, and reproduction in any medium, provided you give appropriate credit to the original author(s) and the source, provide a link to the Creative Commons license, and indicate if changes were made.

\section{References}

Barry, M. M. (2009). Addressing the determinants of positive mental health: Concepts, evidence and practice. International Journal of Mental Health Promotion, 11(3), 4-17.

Bergsma, A., Veenhoven, R., ten Have, M., \& de Graaf, R. (2011). Do they know how happy they are? On the value of self-rated happiness of people with a mental disorder. Journal of Happiness Studies, 12, 793-806.

Biswas-Diener, R., Vitters $\varnothing$, J., \& Diener, E. (2010). The Danish effect: Beginning to explain high wellbeing in Denmark. Social Indicators Research, 97, 229-246.

Brugha, T., Bebbington, P., Tennant, C., \& Hurry, J. (1985). The list of threatening experiences: A subset of 12 life event categories with considerable long-term contextual threat. Psychological Medicine, 15, 189-194.

Catalino, L. I., \& Fredrickson, B. L. (2011). A Tuesday in the life of a flourisher: The role of positive emotional reactivity in optimal mental health. Emotion, 11(4), 938-950.

Caunt, B. S., Franklin, J., Brodaty, N. E., \& Brodaty, H. (2012). Exploring the causes of subjective wellbeing: A content analysis of peoples' recipes for long-term happiness. Journal of Happiness Studies, 14(2), 475-499.

Cicognani, E., Pirini, C., Keyes, C., Joshanloo, M., Rostami, R., \& Nosratabadi, M. (2008). Social participation, sense of community and social well-being: A study on American, Italian and Iranian university students. Social Indicators Research, 89, 97-112.

Costa, P. T, Jr., \& McCrae, R. R. (1992). Revised NEO personality inventory (NEO-PI-R) and the five factor inventory (NEO-FFI): Professional manual. Odessa, Florida: Psychological Assessment Resources Inc.

Deci, E. L., \& Ryan, R. M. (2000). The "what" and "why" of goal pursuits: Human needs and the selfdetermination of behavior. Psychological Inquiry, 11(4), 227-268.

De Graaf, R., ten Have, M., Tuithof, M., \& van Dorsselaer, S. (2013a). First-incidence of DSM-IV mood, anxiety and substance use disorders and its determinants: Results from the Netherlands Mental Health Survey and Incidence Study-2. Journal of Affective Disorders, 149, 100-107. 
De Graaf, R., ten Have, M., \& van Dorsselaer, S. (2010). The Netherlands Mental Health Survey and Incidence Study-2 (NEMESIS-2): Design and methods. International Journal of Methods in Psychiatric Research, 193, 125-141.

De Graaf, R., ten Have, M., van Gool, C., \& van Dorsselaer, S. (2012). Prevalence of mental disorders, and trends from 1996 to 2009. Results from the Netherlands Mental Health Survey and Incidence Study-2. Social Psychiatry and Psychiatric Epidemiology, 47, 203-213.

De Graaf, R., van Dorsselaer, S., Tuithof, M., \& ten Have, M. (2013b). Sociodemographics and psychiatric predictors of attrition in a prospective psychiatric epidemiological study among the general population. Result of the Netherlands Mental Health Survey and Incidence Study-2. Comprehensive Psychiatry, 54(8), 1131-1139.

Delle Fave, A., Brdar, I., Freire, T., Vella-Brodrick, D., \& Wissing, M. P. (2011). The eudaimonic and hedonic compontents of happiness: Qualitative and quantitative findings. Social Indicators Research, 100, 185-207.

Demir, M., \& Weitekamp, L. A. (2007). I am so happy cause today I found my friend: Friendship and personality as predictors of happiness. Journal of Happiness Studies, 8, 181-211.

DeNeve, K. M., \& Cooper, H. (1998). The happy personality: A meta-analysis of 137 personality traits and subjective well-being. Psychological Bulletin, 124(2), 197-229.

Diener, E. (1984). Subjective well-being. Psychological Bulletin, 95(3), 542-575.

Diener, E., Diener, M., \& Diener, C. (1995). Factors predicting the subjective well-being of nations. Journal of Personality and Social Psychology, 69(5), 851-864.

Diener, E., Lucas, R. E., \& Scollon, C. N. (2006). Beyond the hedonic treadmill. Revising the adaptation theory of well-being. American Psychologist, 61(4), 305-314.

Diener, E., \& Ryan, K. (2009). Subjective well-being: a general overview. South African Journal of Psychology, 39(4), 391-406.

Diener, E., \& Seligman, M. E. P. (2002). Very happy people. Psychological Science, 13(1), 81-84.

Diener, E., \& Seligman, M. E. P. (2004). Toward an economy of well-being. Psychological Science in the Public Interest, 5(1), 1-31.

Diener, E., Suh, E. M., Lucas, R. E., \& Smith, H. E. (1999). Subjective well-being: Three decades of progress. Psychological Bulletin, 125, 276-302.

Diener, E., Wirtz, D., Tov, W., Kim-Prieto, C., Choi, D., Oishi, S., et al. (2010). New well-being measures: Short scales to assess flourishing and positive and negative feelings. Social Indicators Research, 97, $143-156$.

Eysenck, S. B. G., Eysenck, H. J., \& Barrett, P. (1985). Revised version of the psychoticism scale. Personality and Individual Differences, 6, 21-29.

Eysenck, S. B. G., White, O., \& Eysenck, H. J. (1976). Personality and mental illness. Psychological Reports, 39, 1011-1022.

Forgeard, M. J. C., Jayawickreme, E., Kern, M. L., \& Seligman, M. E. P. (2011). Doing the right thing: Measuring wellbeing for public policy. International Journal of Wellbeing, 1(1), 79-106.

Fredrickson, B. L., \& Losada, M. F. (2005). Positive affect and the complex dynamics of human flourishing. American Psychologist, 60(7), 678-686.

Helliwell, J., Layard, R., \& Sachs, J. (Eds.). (2013). World Happiness Report 2013. New York: UN Sustainable Development Solutions Network.

Henderson, L. W., Knight, T., \& Richardson, B. (2013). An exploration of the well-being benefits of hedonic and eudaimonic behaviour. The Journal of Positive Psychology, 8(4), 322-336.

Hone, L. C., Jarden, A., Schofield, G. M., \& Duncan, S. (2014). Measuring flourishing: The impact of operational definitions on the prevalence of high levels of wellbeing. International Journal of Wellbeing, 4(1), 62-90.

Huppert, F. A. (2009). Psychological well-being: Evidence regarding its causes and consequences. Applied Psychology: Health and Well-being, 1(2), 137-164.

Huppert, F. A., \& So, T. T. C. (2013). Flourishing across Europe: Application of a new conceptual framework for defining well-being. Social Indicators Research, 110(3), 837-861.

Huta, V., \& Ryan, R. M. (2010). Pursuing pleasure or virtue: The differential and overlapping well-being benefits of hedonic and eudaimonic motives. Journal of Happiness Studies, 11, 735-762.

Kashdan, T. B., Biswas-Diener, R., \& King, L. A. (2008). Reconsidering happiness: The costs of distinguishing between hedonics and eudaimonia. The Journal of Positive Psychology, 3(4), 219-233.

Keyes, C. L. M. (1998). Social well-being. Social Psychology Quarterly, 61(2), 121-140.

Keyes, C. L. M. (2002). The Mental Health Continuum: From languishing to flourishing in life. Journal of Health and Social Research, 43, 207-222.

Keyes, C. L. M. (2005). Mental illness and/or mental health? Investigating axioms of the complete state model of health. Journal of Consulting and Clinical Psychology, 73(3), 539-548. 
Keyes, C. L. M. (2006). Mental health in adolescence: Is America's youth flourishing? American Journal of Orthopsychiatry, 76(3), 395-402.

Keyes, C. L. M. (2007). Promoting and protecting mental health as flourishing. A complementary strategy for improving national mental health. American Psychologist, 62(2), 95-108.

Keyes, C. L. M., Dhingra, S. S., \& Simoes, E. J. (2010). Change in level of positive mental health as a predictor of future risk of mental illness. American Journal of Public Health, 100(12), 2366-2371.

Keyes, C. L. M., \& Shapiro, A. (2004). Social well-being in the United States: A descriptive epidemiology. In O. G. Brim, C. D. Ryff, \& R. C. Kessler (Eds.), How healthy are we? A national study of well-being at midlife. Chicago: University of Chicago Press.

Keyes, C. L. M., Shmotkin, D., \& Ryff, C. D. (2002). Optimizing well-being: The empirical encounter of two traditions. Journal of Personality and Social Psychology, 82(6), 1007-1022.

Keyes, C. L. M., \& Simoes, E. J. (2012). To flourish or not: Positive mental health and all-cause mortality. American Journal of Public Health, 102(11), 2164-2172.

Keyes, C. L. M., Wissing, M., Potgieter, J. P., Temane, M., Kruger, A., \& van Rooy, S. (2008). Evaluation of the mental health continuum-short form (MHC-SF) in setswana-speaking South Africans. Clinical Psychology and Psychotherapy, 15, 181-192.

Kobau, R., Seligman, M. E. P., Peterson, C., Diener, E., Zack, M. M., Chapman, D., et al. (2011). Mental health promotion in public health: Perspectives and strategies from positive psychology. American Journal of Public Health, doi:10.2105/AJPH.2010.300083.

Lamers, S. M. A., Bolier, L., Westerhof, G. J., Smit, F., \& Bohlmeijer, E. T. (2012a). The impact of emotional well-being on long-term recovery and survival in physical illness: A meta-analysis. Journal of Behavioral Medicine, 35, 538-547.

Lamers, S. M. A., Westerhof, G. J., Bohlmeijer, E. T., ten Klooster, P. M., \& Keyes, C. L. M. (2011). Evaluating the psychometric properties of the mental health continuum-short form (MHC-SF). Journal of Clinical Psychology, 67(1), 99-110.

Lamers, S. M. A., Westerhof, G. J., Kovács, V., \& Bohlmeijer, E. T. (2012b). Differential relationships in the association of the Big Five personality traits with positive mental health and psychopathology. Journal of Research in Personality, 46(5), 517-524.

Lehtinen, V., Sohlman, B., \& Kovess-Masfety, V. (2005). Level of positive mental health in the European Union: Results from the Eurobarometer 2002 survey. Clinical Practice and Epidemiology in Mental Health, doi:10.1186/1745-0179-1-9.

Lucas, R. E. (2007). Adaptation and the set-point model of subjective well-being. Does happiness change after major life events? Current Directions in Psychological Science, 16(2), 75-79.

Luhmann, M., Hofmann, W., Eid, M., \& Lucas, R. E. (2012). Subjective well-being and adaptation to life events: A meta-analysis. Journal of Personality and Social Psychology, 102(3), 592-615.

Lyubomirsky, S., King, L., \& Diener, E. (2005a). The benefits of frequent positive affect: Does happiness lead to success? Psychological Bulletin, 131(6), 803-855.

Lyubomirsky, S., Sheldon, K. M., \& Schkade, D. (2005b). Pursuing happiness: The architecture of sustainable change. Review of General Psychology, 9(2), 111-131.

Myers, T. A. (2011). Goodbye, listwise deletion: Presenting hot deck imputation as an easy and effective tool for handling missing data. Communication Methods and Measures, 5(4), 297-310.

Peterson, C., Park, N., \& Seligman, M. (2005). Orientations to happiness and life satisfaction: The full life versus the empty life. Journal of Happiness Studies, 6, 25-41.

Rentflow, P. J., Mellander, C., \& Florida, R. (2009). Happy states of America: A state-level analysis of psychological, economic, and social well-being. Journal of Research in Personality, 43, 1073-1082.

Roepke, A. M. (2013). Gains without pains? Growth after positive events. The Journal of Positive Psychology, 8(4), 280-291.

Rose, G. (2008). Rose's strategy of preventive medicine. Oxford: Oxford University Press.

Ryan, R. M., Huta, V., \& Deci, E. L. (2008). Living well: A self-determination theory perspective on eudaimonia. Journal of Happiness Studies, 9, 139-170.

Ryff, C. D. (1989). Happiness is everything, or is it? Explorations on the meaning of psychological wellbeing. Journal of Personality and Social Psychology, 57(6), 1069-1081.

Ryff, C. D., \& Keyes, C. L. M. (1995). The structure of psychological well-being revisited. Journal of Personality and Social Psychology, 69(4), 719-727.

Ryff, C. D., \& Singer, B. (1998). The contours of positive human health. Psychological Inquiry, 9(1), 1-28.

Ryff, C. D., \& Singer, B. H. (2008). Know thyself and become what you are: A eudaimonic approach to psychological well-being. Journal of Happiness Studies, 9, 13-39.

Sanderman, R., Arrindell, W. A., Ranchor, A. V., Eysenck, H. J., \& Eysenck, S. B. G. (1995). Het meten van persoonlijkheidskenmerken met de Eysenck Personality Questionnaire (EPQ). Groningen: Noordelijk Centrum voor Gezondheidsvraagstukken (RUG). 
Seligman, M. E. P. (2011). Flourish. A new understanding of happiness and well-being-and how to achieve them. London: Nicholas Brealey.

Steel, P., Schmidt, J., \& Shultz, J. (2008). Refining the relationship between personality and subjective wellbeing. Psychological Bulletin, 134(1), 138-161.

Steger, M. F., Kashdan, T. B., \& Oishi, S. (2008). Being good by doing good: Daily eudaimonic activity and well-being. Journal of Research in Personality, 42, 22-42.

Stewart, A. L., Hayes, R. D., \& Ware, J. E. (1988). The MOS short form general health survey. Medical Care, 26(9), 724-735.

Ten Have, M., de Graaf, R., van Weeghel, J., \& van Dorsselaer, S. (2014). The association between common mental disorders and violence: To what extent is it influenced by prior victimization, negative life events and low levels of social support? Psychological Medicine, 44, 1485-1498.

Van der Zee, K. I., \& Sanderman, R. (1993). Het meten van de algemene gezondheidstoestand met de Rand36: Een handleiding. Groningen: Noordelijk Centrum voor Gezondheidsvraagstukken (RUG).

Veenhoven, R. (1996). Developments in satisfaction research. Social Indicators Research, 37, 1-46.

Veenhoven, R. (2008). Healthy happiness: Effects of happiness on physical health and the consequences for preventive health care. Journal of Happiness Studies, 9, 449-469.

Veenhoven, R. (2010). Average happiness in 149 nations 2000-2009. World Database of Happiness. Rank report Average Happiness. Retrieved June 26, 2013, from World Database of Happiness Website http://worlddatabaseofhappiness.eur.nl/hap_nat/findingreports/RankReport_AverageHappiness.php

Ware, J. E., Kosinski, M., \& Keller, S. D. (1994). Physical and mental health summary scales: A user's manual. Boston, MA: New England Medical Center, The Health Institute.

Waterman, A. S. (1993). Two conceptions of happiness: Contrasts of personal expressiveness (eudaimonia) and hedonic enjoyment. Journal of Personality and Social Psychology, 64(4), 678-691.

Waterman, A. S. (2008). Reconsidering happiness: A eudaimonist's perspective. The Journal of Positive Psychology, 3(4), 234-252.

Waterman, A. S., Schwartz, S. J., \& Conti, R. (2008). The implications of two conceptions of happiness (hedonic enjoyment and eudaimonia) for the understanding of intrinsic motivation. Journal of Happiness Studies, 9, 41-79.

Weiss, A., Bates, T. C., \& Luciano, M. (2008). Happiness is a personal(ity) thing: The genetics of personality and well-being in a representative sample. Psychological Science, 19, 205-210. 